\title{
International Consensus on Antinuclear Antibody em Portugal
}

\section{International Consensus on Antinuclear Antibody Patterns in Portugal}

Maria José SOUSA $\triangle^{1,2}$, Esmeralda NEVES ${ }^{3}$, Otília FIGUEIRAS ${ }^{3}$, Ana Paula CRUZ ${ }^{4}$, Isabel FERNANDES ${ }^{5}$, Alexandra MENDES ${ }^{5}$, Maria do Céu SANTOS ${ }^{6}$, Rosário CUNHA ${ }^{7}$, Lídia MAGUEIJO ${ }^{8}$, Cláudia PRATAS ${ }^{9}$, Ana MIRANDA ${ }^{10}$, Rita RIBEIRO 1

Acta Med Port 2021 May;34(5):347-354 - https://doi.org/10.20344/amp.13121

RESUMO

Introdução: A pesquisa de autoanticorpos em células HEp-2 através de imunofluorescência indireta é o teste padrão atualmente aceite como a ferramenta central para o diagnóstico das doenças autoimunes sistémicas. O International Consensus on Antinuclear Antibody (ANA) Patterns tem como objetivo principal alcançar um consenso na nomenclatura e na descrição dos diferentes padrões morfológicos de anticorpos antinucleares. Este trabalho tem como objetivo ampliar o projeto do International Consensus on ANA Patterns de forma a estabelecer um consenso em Portugal para a sua nomenclatura, procurando contribuir para a harmonização no diagnóstico autoimune e promover a qualidade diagnóstica nas doenças reumáticas sistémicas autoimunes.

Material e Métodos: Os laboratórios participantes identificaram cada designação de padrão citoplasmático e nuclear do International Consensus on ANA Patterns (incluindo o código padrão anti-célula), e fizeram corresponder a cada uma a respetiva nomenclatura portuguesa em uso. Os resultados foram agregados e serviram de base ao trabalho de harmonização da nomenclatura. Seguiram-se reuniões de consenso, num processo iterativo até à redação de uma proposta final consensualizada.

Resultados: A concordância prévia entre laboratórios era superior a $75 \%$ para 23 do total de 29 padrões anti-célula. O grau em que cada laboratório está alinhado com a referência internacional do International Consensus on ANA Patterns varia entre $22,1 \%$ e $100 \%$. Foi possível elaborar uma versão consensualizada da nomenclatura do International Consensus on ANA Patterns para Portugal.

Discussão: Existia uma boa base de consenso para a nomenclatura do International Consensus on ANA Patterns, mas com diferenças importantes em algumas das traduções da terminologia. O estudo realça a necessidade de colaboração entre laboratórios para uma descrição inequívoca dos resultados laboratoriais.

Conclusão: Este trabalho mostra o potencial positivo da colaboração entre laboratórios para gerar consensos que contribuam para a melhoria do diagnóstico e acompanhamento dos doentes.

Palavras-chave: Anticorpos Antinucleares/análise; Portugal; Técnica Indireta de Fluorescência para Anticorpo/métodos

\section{ABSTRACT}

Introduction: Screening for autoantibodies in HEp-2 cells by indirect immunofluorescence is currently accepted as the gold-standard test for the diagnosis of systemic autoimmune diseases. The main objective of the International Consensus on ANA Patterns is to achieve a consensus on the nomenclature and description of antinuclear antibody morphological patterns. This work aims to build on the International Consensus on ANA Patterns project to establish a nomenclature consensus in Portugal, thus contributing to harmonization in autoimmune diagnosis and promoting diagnostic quality in autoimmune systemic rheumatic diseases.

Material and Methods: Participating laboratories identified all the nuclear and cytoplasmic pattern designations in the International Consensus on ANA Patterns (including the anti-cell pattern code), and matched them with the corresponding Portuguese nomenclature in use. The results were aggregated and used as a foundation for nomenclature harmonization work. Consensus meetings followed an iterative process, until a final consensual proposal was drafted.

Results: Prior agreement between laboratories was over $75 \%$ for 23 of the total 29 anti-cell patterns. The degree to which each laboratory is aligned with the International Consensus on ANA Patterns international reference ranges from $22.1 \%$ to $100 \%$. It was possible to write a consensual version of the International Consensus on ANA Patterns nomenclature for Portugal.

Discussion: There was a good consensus basis for the nomenclature in the International Consensus on ANA Patterns, despite relevant differences with some translations. The study highlights the need for collaboration among laboratories towards an unambiguous description of laboratory results.

Conclusion: This study shows that there is good potential for collaboration between laboratories in order to produce the consensus needed to improve diagnosis and patient follow-up.

Keywords: Antibodies, Antinuclear/analysis; Fluorescent Antibody Technique, Indirect/methods; Portugal

\footnotetext{
1. Departamento de Imunopatologia e Autoimunidade. Centro de Medicina Laboratorial Germano de Sousa. Lisboa. Portugal.

2. Departamento de Medicina. Faculdade Ciências Médicas/ Nova Medical School. Lisboa. Portugal.

3. Departamento de Patologia. Serviço de Imunologia. Centro Hospitalar e Universitário do Porto. Porto. Portugal.

4. Laboratório de Imunologia Humoral. Serviço de Patologia Clínica. Centro Hospitalar Vila Nova de Gaia/Espinho. Vila Nova de Gaia. Portugal.

5. Laboratório de Imunologia. Serviço de Patologia Clínica. Centro Hospitalar Lisboa Ocidental. Lisboa. Portugal.

6. Seç̧ão de Imunologia. Serviço de Patologia Clínica. Centro Hospitalar Lisboa Central. Lisboa. Portugal.

7. Laboratório de Imunologia. Serviço de Patologia Clínica. Centro Hospitalar Universitário de Coimbra. Coimbra. Portugal.

8. Departamento de Imunologia. AFFIDEA. Laboratório de Castelo Branco. Castelo Branco. Portugal.

9. Departamento de Análises Especiais. UNILABS. Laboratório Carlos Torres. Porto. Portugal.

10. Departamento de Serologia e Autoimunidade. Centro Hospitalar Lisboa Norte. Lisboa. Portugal.

$\triangle$ Autor correspondente: Maria José Sousa. investigacaogs@gmail.com
}

Recebido: 18 de novembro de 2019 - Aceite: 17 de fevereiro de 2020 - First published: 02 de março de 2021 - Online issue published: 03 de maio de 2021 Copyright @ Ordem dos Médicos 2021 


\section{INTRODUÇÃO}

A pesquisa de autoanticorpos em células HEp-2 através da técnica de imunofluorescência indireta (IFI), tem sido utilizada desde 1950, altura das primeiras descrições feitas por Coons e Kaplan. ${ }^{1}$ Tornou-se o teste padrão quando migrou dos tecidos animais para as células epiteliais humanas HEp-2 e é atualmente aceite como a ferramenta central para o diagnóstico das doenças autoimunes sistémicas. ${ }^{2}$

Em 2013, um grupo de peritos internacionais (especialistas de laboratório, cientistas e clínicos), elaborou um conjunto de recomendações para a correta avaliação e interpretação de autoanticorpos celulares, historicamente conhecidos como anticorpos antinucleares (ANA), identificando a imunofluorescência indireta como o método de referência para o screening de ANA. Desde esse momento, a deteção de anticorpos orientada para elementos nucleares e não nucleares passou a ser designada como ANA, ${ }^{2}$ ou HEp-2 IFI. ${ }^{3}$

Em 2006, Alan Wiik afirmou, no artigo Guidelines for antinuclear antibody testing, que a terminologia ANA tem sido usada para todos os anticorpos celulares que podem ser visualizados através da IFI no substrato $\mathrm{HEp}-2,{ }^{4}$ e que apesar da célula conter milhares de proteínas diferentes, poucas têm propriedades autoantigénicas. Subsequente- mente, os ANA podem ser divididos em cinco grupos: i. os que reconhecem organelos do nucleoplasma, ii. nucléolo, iii. antigénios da membrana celular, iv. aparelho mitótico e v. citoplasma. ${ }^{4}$ Os diferentes tipos de ANA geram padrões diferentes e individualmente característicos nas células HEp2, dependendo da localização celular e das propriedades do antigénio alvo presente na amostra.

Em 2014, foi criada, em São Paulo, no Brasil, a iniciativa ICAP (International Consensus on Antinuclear Antibody (ANA) Patterns), decorrente do $12^{\circ}$ Encontro sobre Autoimunidade e Autoanticorpos (IWAA). Esta iniciativa foi organizada por membros do Comité de Padronização dos Autoanticorpos (ASC), que integra o Comité de Avaliação da Qualidade e Padronização da União Internacional das Sociedades de Imunologia, este último associado à Organização Mundial de Saúde (OMS). O comité ICAP tem como objetivo principal alcançar um consenso na nomenclatura e na descrição dos diferentes padrões morfológicos ANA, com detalhes altamente variáveis quando observados por IFI em células HEp-2. ${ }^{5}$ Outro objetivo importante é alcançar uma harmonização na forma como os resultados dos testes ANA são reportados, ${ }^{6}$ obtida através da descrição dos padrões e sub-padrões, aos quais são atribuídos códigos

Tabela 1 - Antigénios-alvo e doenças associadas para os padrões nucleares

\begin{tabular}{|c|c|c|c|}
\hline Padrão nuclear (ICAP) & Código & Antigenos associados & Doenças associadas \\
\hline Homogéneo & AC-1 & dsDNA, nucleossomas, histonas & $\begin{array}{l}\text { SLE, lúpus induzido por drogas, artrite } \\
\text { idiopática juvenil }\end{array}$ \\
\hline Mosqueado & $\mathrm{AC}-2,4,5$ & $\begin{array}{l}\text { hnRNP, U1RNP, Sm, SS-A/Ro (Ro60), } \\
\text { SS-B/La, RNA polimerase III, Mi-2, Ku }\end{array}$ & MCTD, SLE, SJ, DM, sobreposição SSc/PM \\
\hline Mosqueado fino denso & AC-2 & DFS70/LEDGF & Raro em SLE, SjS, SSc \\
\hline Mosqueado fino & AC-4 & $\begin{array}{l}\text { SS-A/Ro (Ro60), SS-B/La, Mi-2; TIF1Y, } \\
\text { TIF1 } \beta \text {, Ku, RNA helicase A, Proteína de } \\
\text { replicação A }\end{array}$ & SjS, SLE, DM, Sobreposição SSc/PM \\
\hline Mosqueado grosseiro & AC-5 & hnRNP, U1RNP, Sm, RNA polimerase III & MCTD, SLE, SSc \\
\hline Centrómero & AC-3 & CENP-A/B (C) & SSc cutânea limitada, CBP \\
\hline Pontos nucleares discretos & AC- 6,7 & & \\
\hline Múltiplos pontos nucleares & AC-6 & Sp100, PML proteínas, MJ/NXP-2 & CBP, SARD, PM/DM \\
\hline Raros pontos nucleares & AC-7 & p80-coilina, SMN & $\begin{array}{l}\text { SjS, SLE, SSc, PM, indivíduos } \\
\text { assintomáticos }\end{array}$ \\
\hline Nucleolar & $A C-8,9,10$ & & \\
\hline Nucleolar homogéneo & AC-8 & $\begin{array}{l}\mathrm{PM} / \mathrm{Scl}-75, \mathrm{PM} / \mathrm{Scl}-100, \mathrm{Th} / \mathrm{To}, \mathrm{B} 23 / \\
\text { nucleofosfomina, nucleolina, No55/SC65 }\end{array}$ & SSc, sobreposição SSc/PM \\
\hline Nucleolar aglomerado & AC-9 & U3-snoRNP/fribrilarina & SSc \\
\hline Nucleolar ponteado & AC-10 & RNA polimerase I, hUBF/NOR-90 & SSc, SjS \\
\hline Envelope nuclear & $A C-11,12$ & & \\
\hline Membrana nuclear linear & AC-11 & $\begin{array}{l}\text { Laminas } A, B, C \text {, ou proteínas associadas a } \\
\text { laminas }\end{array}$ & SLE, SjS, artrites seronegativas \\
\hline $\begin{array}{l}\text { Membrana nuclear ponteada } \\
\text { (complexo poro-nuclear) }\end{array}$ & $\mathrm{AC}-12$ & $\begin{array}{l}\text { Proteínas do complexo poro nucleares } \\
\text { (i.e., gp210) }\end{array}$ & CBP \\
\hline Pleomórfico & $A C-13,14$ & & \\
\hline Pleomórfico (tipo PCNA) & AC-13 & PCNA & SLE, outras condições \\
\hline Pleomórfico (tipo CENP-F) & AC-14 & CENP-F & Cancro, outras condições \\
\hline
\end{tabular}

SLE: lúpus eritematoso disseminado; MCTD: doenças mistas do tecido conjuntivo; SjS: síndrome de Jorgen; DM: dermatomiosite; Sobreposição SSc/PM: síndrome de sobreposição entre esclerodermia/poliomiosite; SSc: esclerodermia; SSc cutânea limitada: esclerodermia na forma cutânea limitada; CBP: colangite biliar primária; SARD: doenças autoimunes reumáticas sistémicas; PM: poliomiosite; PM/DM: poliomiosite/dermatomiosite 
padrão anti-célula (AC) no intervalo de AC-1 a AC-29, classificados em três categorias de manchas: i. padrão nuclear, ii. padrão citoplasmático e iii. padrão mitótico. A iniciativa tem partilhado o seu trabalho na internet, com traduções em inglês, francês, italiano, espanhol, holandês, mandarim e português (de Portugal e do Brasil), disponíveis em www. anapatterns.org.

\section{Consenso internacional atual \\ Padrões nucleares}

Os padrões nucleares são definidos como qualquer coloração dos núcleos das células HEp-2 em interfase HEp2. A nomenclatura para os padrões nucleares é baseada principalmente na reatividade observada no nucleoplasma (e.g. homogéneo ou mosqueado) e nos subcomponentes nucleares reconhecidos (e.g. centrómero ou nucleolar). Os padrões nucleares incluem padrões homogéneo, mosqueado, centrómero, pontos nucleares discretos, nucleolar, membrana nuclear e padrões pleomórficos. O Dense Fine Speckled 70 (DFS70) pertence ao grupo mosqueado. O padrão do centrómero pertence aos pontos nucleares discretos, mas recebe o seu próprio grupo devido ao seu padrão característico e ocorrência frequente num determinado contexto clínico. Os grupos nucleares de padrões estão ainda divididos em subgrupos, como fino ou grosseiro, múltiplos ou raros pontos nucleares, nucleolar homogéneo, aglomerado ou ponteado; membrana nuclear linear ou ponteada e padrões pleomórficos semelhantes a Proliferating Cell Nuclear Antigen (PCNA) ou Centromere
Protein F (CENP-F). Esta classificação do padrão nuclear fornece informações sobre os prováveis antigénios-alvo e, assim, possíveis indicações da doença (Tabela 1). A título de exemplo, o padrão homogéneo surge em reações com componentes da cromatina, como DNA de cadeia dupla, histonas e/ou nucleossomas. Estes autoanticorpos estão associados ao LES, lúpus induzido por drogas e artrite idiopática juvenil. Outras reações nucleares podem ajudar os clínicos a delimitar a DMTC, SjS, ES, PM, DM, CBP ou outras doenças autoimunes. Os padrões mistos podem ocorrer quando mais de um autoanticorpo estiver presente na amostra dos doentes, como autoanticorpos para ambos os centrómeros (nucleares) e mitocôndrias (citoplasmáticas), que co-ocorrem frequentemente com CBP.

\section{Padrões citoplasmáticos}

Os padrões citoplasmáticos são definidos a partir de qualquer coloração do citoplasma HEp-2. A nomenclatura é primariamente baseada na reatividade observada no citoplasma (e.g. filamentoso ou granular) e na estrutura citoplasmática reconhecida (e.g. anéis e bastonetes). Os cinco principais padrões citoplasmáticos incluem os filamentosos, granular, reticular/do tipo mitocondrial (AMA), polar/do tipo Golgi e anéis e bastonetes. O padrão filamentoso é ainda subdividido em linear, fibrilar e segmentar, enquanto o padrão granular é subcategorizado em grânulos isolados, fino denso e fino. Os autoanticorpos citoplasmáticos de diferentes especificidades encontram-se numa variedade de doenças (Tabela 2), incluindo DMTC, PM, DM, LES, ES,

Tabela 2 - Antigénios-alvo e doenças associadas para os padrões citoplasmáticos

\begin{tabular}{|c|c|c|c|}
\hline Padrão nuclear (ICAP) & Código & Antigenos associados & Doenças associadas \\
\hline Fibrilar & $A C-15,16,17$ & & \\
\hline Linear/ actina & AC-15 & $\begin{array}{l}\text { Actina, miosina não muscular } \\
\text { MCTD }\end{array}$ & $\begin{array}{l}\text { MCTD, hepatite crónica ativa, cirrose hepática, } \\
\text { miastenia gravis, doença de Crohn, CBP, hemodiálise } \\
\text { a longo prazo, raro em SARD, outro que não seja } \\
\text { MCTD }\end{array}$ \\
\hline Filamentoso/ microtúbulos & AC-16 & Vimentina, citoqueratinas & $\begin{array}{l}\text { Infeções ou condições inflamatórias, hemodiálise } \\
\text { a longo prazo, doença hepática alcoólica, SARD, } \\
\text { psoríase, controlos saudáveis }\end{array}$ \\
\hline Segmentar & AC-17 & $\begin{array}{l}\text { Alfa-actina, vinculina, } \\
\text { tropomiosina }\end{array}$ & Miastenia gravis, doença de Crohn, colite ulcerosa \\
\hline Mosqueado & AC-18, 19, 20 & & \\
\hline Grânulos isolados & AC-18 & SGW182, Su/Ago2, Ge-1 & CBP, SARD, condições neurológicas e autoimunes \\
\hline Fino granular denso & AC-19 & $\begin{array}{l}\text { PL-7, PL-12, proteína } \\
\text { ribossomal P }\end{array}$ & $\begin{array}{l}\text { "Síndrome anti-sintetase", PM/DM, SLE, SLE juvenil, } \\
\text { SLE neuropsiquiátrico }\end{array}$ \\
\hline Fino granular & AC-20 & jo-1/histidil-tRNA sintetase & $\begin{array}{l}\text { Síndrome anti-sintetase, PM/DM, SSc limitado, } \\
\text { derrame pleural idiopático }\end{array}$ \\
\hline Reticular/AMA & AC-21 & $\begin{array}{l}\text { PDC-E2/M2, BCOADC-E2, } \\
\text { OGDC-E2, Subunidade alfa E1 } \\
\text { do PDC, E3BP/proteína X }\end{array}$ & Comum em CBP, SSc, raro em outras SARD \\
\hline Polar (tipo Golgi) & AC-22 & $\begin{array}{l}\text { Giantina/macrogolgina, } \\
\text { golgina-95/GM130, golgina-160, } \\
\text { golgina-97, golgina-245 }\end{array}$ & $\begin{array}{l}\text { Raro em SjS, SLE, RA, MCTD, GPA, ataxia cerebelar } \\
\text { idiopática, degeneração cerebelar paraneoplásica, } \\
\text { infeções virais }\end{array}$ \\
\hline Anéis e bastonetes & AC-23 & IMPDH2, outras & $\begin{array}{l}\text { Pacientes com HCV post-IFN/ terapia com ribavirina, } \\
\text { raro em SLE, Hashimoto e indivíduos saudáveis }\end{array}$ \\
\hline
\end{tabular}

MCTD: doenças mistas do tecido conjuntivo; CBP: colangite biliar primária; SARD: doenças autoimunes reumáticas sistémicas; PM/DM: poliomiosite/dermatomiosite; SLE: lúpus eritematoso disseminado; SSc: esclerodermia; SSc: esclerodermia forma cutânea limitada; SjS: síndrome de Sjörgen; RA: artrite reumatóide; GPA: granulomatose com poliangiite; HCV post-IFN: hepatite $C$ pós-interferon 
Tabela 3 - Antigénios-Alvo e doenças associadas para os padrões mitóticos

\begin{tabular}{|c|c|c|c|}
\hline Padrão nuclear (ICAP) & Código & Antigenos associados & Doenças associadas \\
\hline Centrossoma & $\mathrm{AC}-24$ & $\begin{array}{l}\text { Pericentrina, nineína, Cep250, } \\
\text { Cep110, enolase }\end{array}$ & $\begin{array}{l}\text { Raro em SSc, fenómeno de Raynaud, infeções (viral e } \\
\text { micoplasma) }\end{array}$ \\
\hline Fuso mitótico & AC-25 & HsEg5 & Raro em SjS, SLE, outras SARD \\
\hline Fuso mitótico (NuMA-1) & $\mathrm{AC}-26$ & Centrofilina & SjS, SLE, outras \\
\hline Ponte Intercelular & $\mathrm{AC}-27$ & $\begin{array}{l}\text { Aurora cinase B, CENP-E, } \\
\text { MAS-2, KIF-14, MKLP-1 }\end{array}$ & Raro em SSc, fenómeno de Raynaud, malignidade \\
\hline Envelope cromossómico & AC-28 & Histona H3 modificada, MCA-1 & $\begin{array}{l}\text { Raro no lúpus eritematoso discóide, leucemia linfocítica } \\
\text { crónica, SjS, e polimialgia reumática }\end{array}$ \\
\hline
\end{tabular}

SSc: esclerodermia; SjS: síndrome de Sjörgen; SLE: lúpus eritematoso disseminado; SARD: doenças autoimunes reumáticas sistémicas

CBP, doença de Crohn, colite ulcerosa e miastenia gravis. Os padrões citoplasmáticos devem ser descritos nos resultados dos doentes e não reportados como ANA negativos.

\section{Padrões mitóticos}

Os padrões mitóticos são definidos como padrões associados aos domínios celulares claramente relacionados com a mitose. Os padrões mitóticos incluem o centrossoma, o fuso mitótico com o subpadrão do aparelho mitótico nuclear (NuMA-1), a ponte intercelular e o envelope cromossómico. Alguns padrões mitóticos (e.g., centrossoma) não estão associados exclusivamente à mitose, mas exibem características muito distintas nas células mitóticas. Os anticorpos mitóticos são ocorrências raras em doenças como a ES, LES, SjS e fenómeno de Raynaud (Tabela 3).

\section{Confirmação dos resultados do teste por IFI}

Os resultados positivos no teste de ANA por IFI devem ser confirmados através de testes específicos adicionais, usando técnicas diferentes, como immunoblot multiplex ou enzyme-linked immunosorbent assay (ELISA) (Fig. 1).

\section{Perspetivas}

A iniciativa do ICAP lançou as bases para a criação de uma nomenclatura harmonizada e para a melhoria da descrição dos resultados dos testes ANA. Existem, naturalmente, questões pendentes para serem abordadas em edições futuras, que incluem a classificação de padrões compostos e mistos (e.g., topoisomerase I (Scl-70)), a inclusão de padrões raros, ou se os anticorpos citoplasmáticos e mitóticos devem ser classificados como positivos para ANA ou reportados separadamente. A otimização das estratégias de confirmação também terá de ser analisada. O consenso é um processo contínuo que se espera que amadureça para um padrão global que incorpore contribuições de laboratórios e de clínicos de todo o mundo. Outra contribuição importante para a harmonização dos ANA é o uso crescente de software de reconhecimento de padrões nos laboratórios. A automação da avaliação IFI aumenta a consistência entre diferentes laboratórios e aumenta a velocidade e a eficiência do procedimento de avaliação. Adicionalmente, o software também pode ser adaptado, à medida que as normas que orientam a interpretação evoluem.

Devido ao facto dos ANA surgirem numa grande variedade de doenças autoimunes sistémicas, incluindo lupus sistémico eritematoso (LSE), doença mista do tecido conjuntivo (DMTC), síndrome de Sjörgen (SjS), esclerose sistémica (ES), polimiosite (PM), dermatomiosite (DM) e colangite biliar primária (CBP), sendo um critério importante para diagnosticar e discriminar estas doenças, consideramos a padronização e a harmonização no diagnóstico autoimune

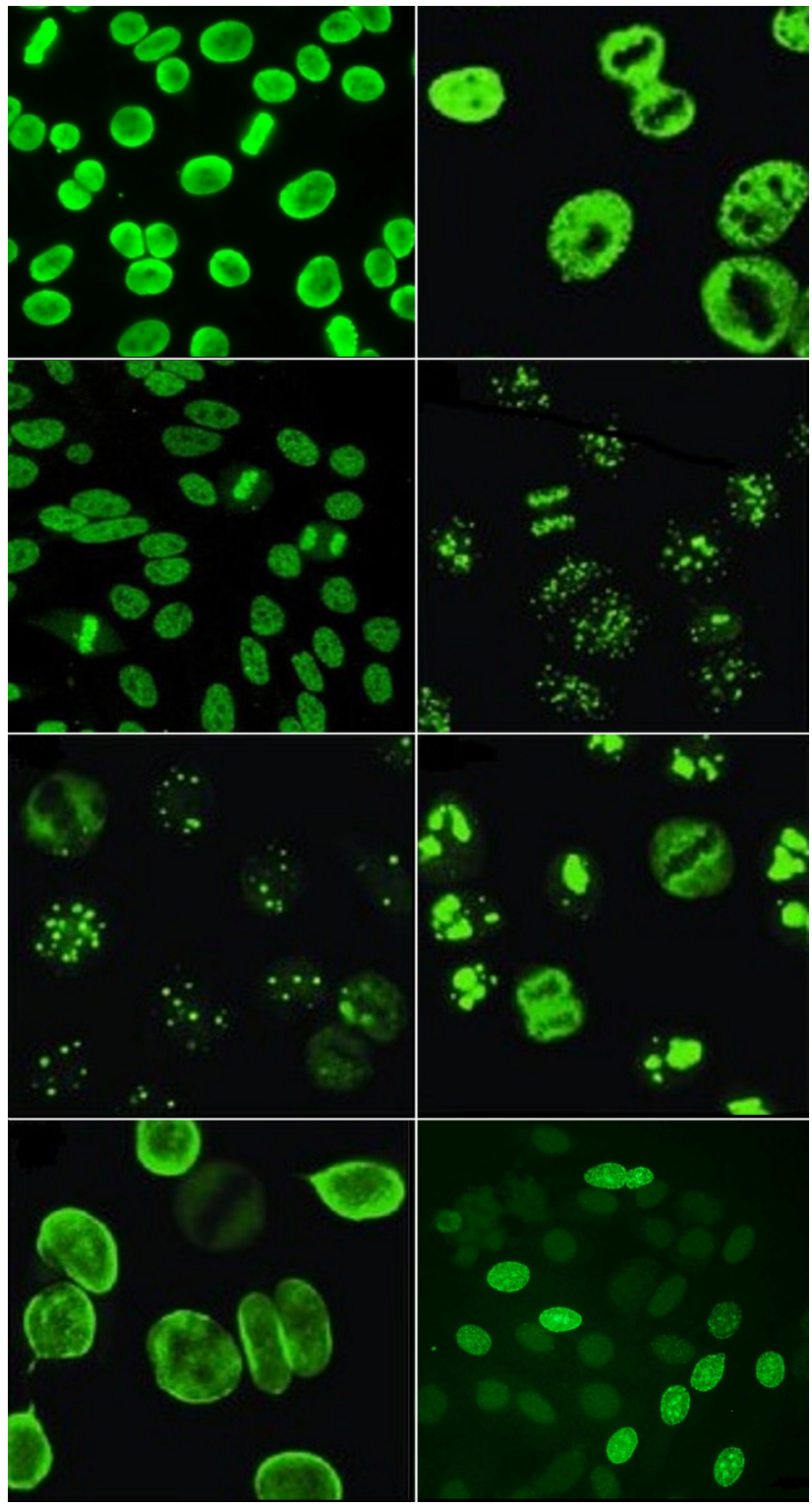

Figura 1 - Algoritmo para pesquisa reflexa de autoanticorpos guiada pelos padrões nucleares 
um marco para a qualidade diagnóstica nas doenças reumáticas sistémicas autoimunes.

Além da participação neste grupo de trabalho e das traduções publicadas, um grupo de peritos Portugueses decidiu ampliar o projeto do ICAP de forma a estabelecer um consenso em Portugal para a sua nomenclatura com vista a eliminar as atuais discrepâncias na descrição de resultados, e a permitir uma melhoria tanto na qualidade do diagnóstico como na comunicação entre os profissionais envolvidos nos processos de diagnóstico e tratamento.

\section{MATERIAL E MÉTODOS}

Para este trabalho criámos um grupo de consenso que incluiu médicos e farmacêuticos a trabalhar na área da Medicina Laboratorial em nove locais diferentes de Portugal, com vasta experiência no teste por IFI e padrões ANA. Do total, seis são laboratórios públicos (hospitais ou hospitais universitários) e os três restantes são privados, selecionados devido à sua capacidade e vasta experiência com o teste IFI em células HEp-2.

Pedimos a todos os laboratórios participantes para identificarem cada designação de padrão citoplasmático e nuclear do ICAP (incluindo o código AC), com a nomenclatura Portuguesa correspondente em uso, para a qual não havia consenso ou referência prévia.

Antes da primeira reunião de consenso, agregámos e enviámos os resultados de todos os laboratórios para o grupo de trabalho, num relatório com a estatística descritiva. Foi também descrita a taxa de concordância para cada padrão, permitindo que todos os participantes avaliassem o seu nível de consenso e identificassem a terminologia mais comumente utilizada antes da segunda fase deste trabalho.

Seguiram-se várias reuniões de consenso tendo por base o primeiro relatório, num processo iterativo apoiado por documentos circulados por correio eletrónico, até à redação de uma proposta. Após o acordo respeitante à nomenclatura em português, foi concluída uma versão final para o consenso do ICAP em Portugal, com a concordância dos nove laboratórios para todas as designações citoplasmáticas e nucleares, listadas em baixo.

Os autores excluíram a necessidade de fazer um pedido de aprovação deste estudo em sede de comissão de ética, por este não envolver doentes ou a utilização de informação privada ou sensível.

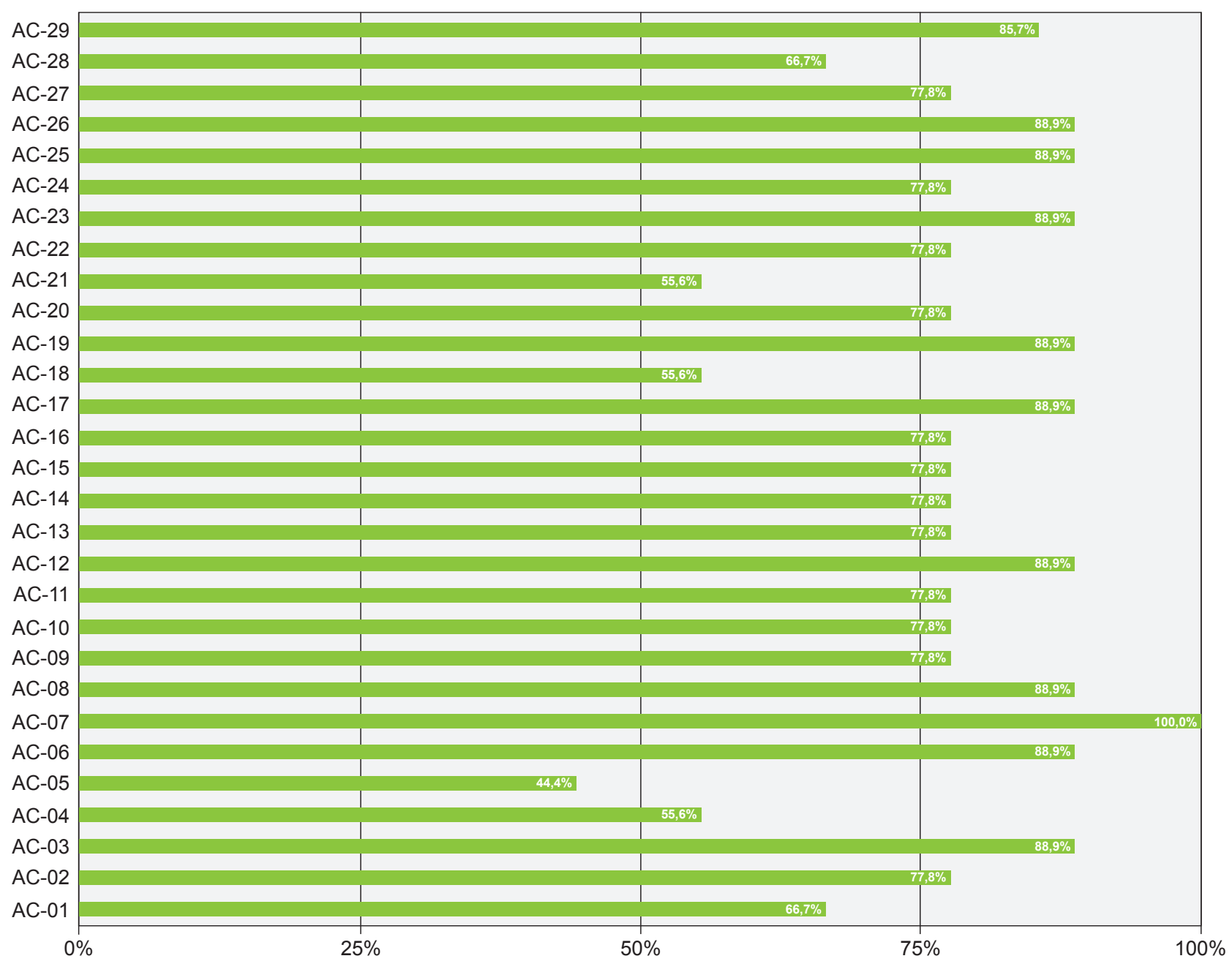

Figura 2 - Concordância da nomenclatura para cada padrão AC, entre os laboratórios. As barras indicam o nível de concordância entre laboratórios para a nomenclatura usada em cada padrão AC. 


\section{RESULTADOS}

Globalmente, a concordância entre os laboratórios portugueses é alta, com uma concordância inferior a $75 \%$ (Fig. 2), à exceção de seis padrões AC. Não há padrões com concordância no intervalo do primeiro quartil e há um padrão no segundo quartil. Vinte e três padrões $(79,3 \%)$, estão dentro do intervalo do último quartil. Para os AC referentes aos padrões mitóticos, o nível mais baixo de concordância é de $66,7 \%$, enquanto o nível mais alto é de $88,9 \%$. Apenas um padrão nuclear (AC-07) reuniu $100 \%$ de concordância entre laboratórios. Este resultado é obtido no mesmo grupo (padrões nucleares), onde podemos observar o único nível de concordância abaixo de 50\% (AC-05), e onde a faixa de concordância também é maior entre os três grupos (44,4\% - $100 \%)$. Os padrões citoplasmáticos variam entre $55,6 \%$ a $88,9 \%$, mas a grande maioria dos níveis de concordância verifica-se acima de $75 \%$.

Para além dos níveis de concordância em relação à nomenclatura, foi também avaliada a homologia entre os laboratórios antes do processo de consenso (Fig. 3). Verificou-se que apesar dos níveis altos de concordância global para os padrões de AC no país, o grau em que cada laboratório estava alinhado com a referência internacional do ICAP variava consideravelmente.Apenas dois laboratórios apresentaram um nível de concordância inferior a $75 \%$. Todos os outros $(n=7)$ apresentaram uma concordância acima dos $75 \%$.

No final do processo, anteriormente descrito na metodologia, foi elaborada uma lista com a nomenclatura acordada traduzida para português, como base de consenso para todos os laboratórios participantes (Tabela 4).

\section{DISCUSSÃO}

Os resultados mostram uma concordância acima dos $75 \%$ para 23 dos 29 padrões AC, confirmando que, anteriormente ao nosso estudo, já existia uma boa base de consenso para o ICAP no nosso país. Este consenso é de alguma forma similar a estudos de âmbito nacional no universo da avaliação da qualidade, no binómio que inclui o teste utilizado e a forma de descrever os resultados. ${ }^{7}$ No entanto, encontrámos diferenças em traduções da terminologia usada entre os diversos laboratórios, com impacto na forma como os resultados são relatados, um fenómeno anteriormente identificado e amplamente discutido. ${ }^{8-10}$

Outra dimensão relevante dos nossos resultados está associada à evidência de diferenças na nomenclatura utilizada para o conjunto de todos os padrões AC, comparada com a referência internacional do ICAP, antes do processo de consenso. O grau de concordância variou entre os $24 \%$ e os $100 \%$, o que poderá ter impacto na correta interpretação de resultados no contexto da partilha de dados entre instituições, justificando, anteriormente, processos similares de consenso de âmbito internacional. ${ }^{5}$

Uma das limitações deste estudo é a ausência de investigação sobre os fatores que podem ter influenciado os níveis de homologia entre os laboratórios, incluindo a localização geográfica, a cultura e a estrutura organizacional dos laboratórios, e o trabalho anterior com o ICAP. Estes fatores não foram abordados aqui devido ao âmbito específico deste trabalho e à complexidade metodológica envolvida nessa avaliação, e devem ser objeto de uma futura investigação. Outra limitação é o número de laboratórios envolvidos. Apesar dos exemplos de processos de consenso similares serem internacionais, ${ }^{5}$ com universos que têm como unidade de estudo países e não laboratórios, consideramos como princípio positivo o aumento do número de laboratórios participantes nos processos de consenso. Aumentará, assim, a probabilidade de maior impacto a médio e a longo prazo.

Este estudo permitiu evidenciar a importância da adoção de terminologia de consenso na emissão de resultados dos ANA e destacar a importância de trabalhos multicêntricos, diminuindo os riscos associados à falta de harmonização, anteriormente identificada. ${ }^{11}$

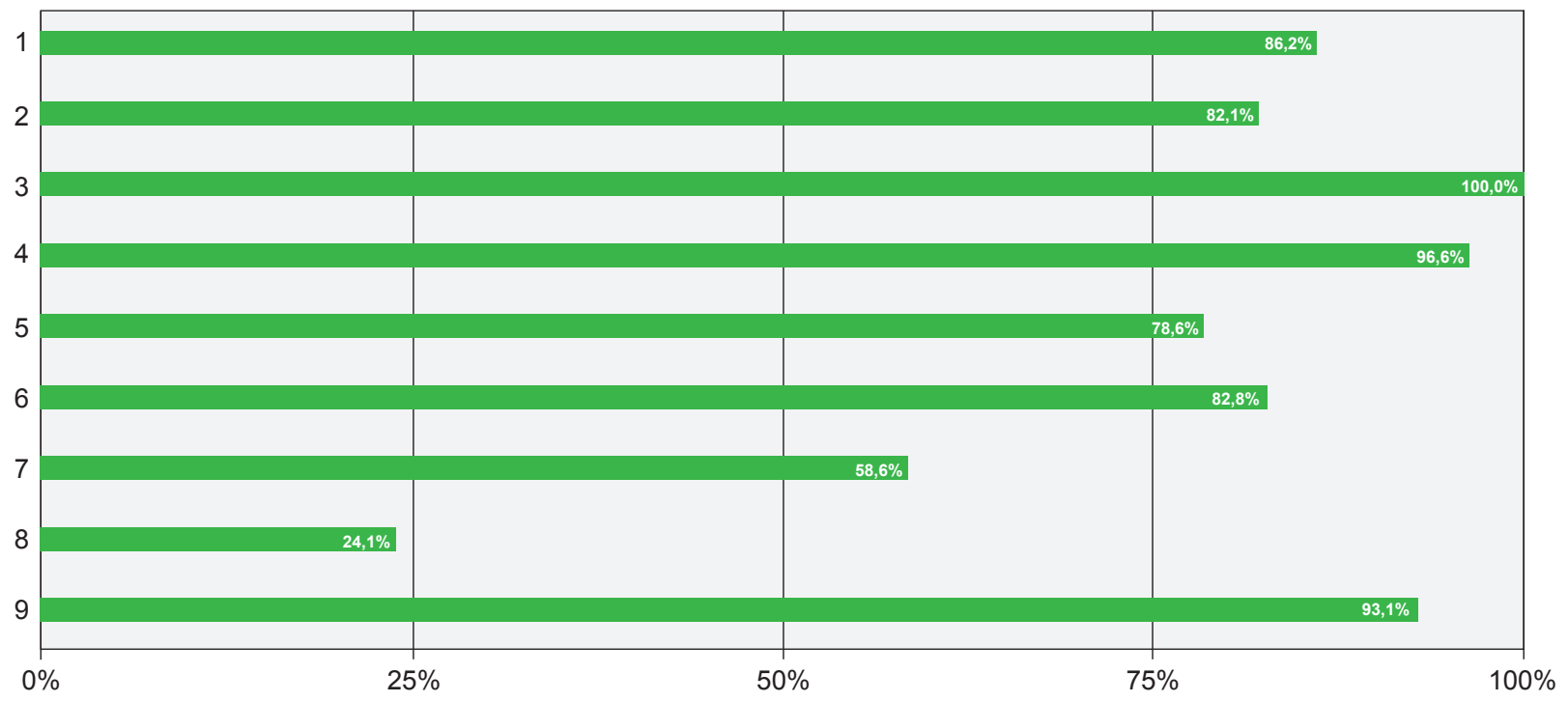

Figura 3 - Homologia da nomenclatura, por laboratório. As barras indicam o nível de concordância com a nomenclatura de todos os padrões AC, por laboratório, antes do processo de consenso. 
Tabela 4 - Nomenclatura original em inglês e tradução final de consenso para os padrões AC

\begin{tabular}{|c|c|c|}
\hline & Pattern & Padrão (consenso para Portugal) \\
\hline AC-01 & Nuclear homogeneous & Nuclear homogéneo \\
\hline AC-02 & Nuclear dense fine speckled & Nuclear mosqueado fino denso \\
\hline AC-03 & Centromere & Centrómero \\
\hline AC-04 & Nuclear fine speckled & Nuclear mosqueado fino \\
\hline AC-05 & Nuclear large/coarse speckled & Nuclear mosqueado grosseiro \\
\hline AC-06 & Multiple nuclear dots & Múltiplos pontos nucleares \\
\hline AC-07 & Few nuclear dots & Raros pontos nucleares \\
\hline AC-08 & Homogeneous nucleolar & Nucleolar homogéneo \\
\hline AC-09 & Clumpy nucleolar & Nucleolar aglomerado \\
\hline AC-10 & Punctate nucleolar & Nucleolar ponteado \\
\hline AC-11 & Smooth nuclear envelope & Membrana nuclear linear \\
\hline AC-12 & Punctate nuclear envelope & Membrana nuclear ponteada (complexo poro-nuclear) \\
\hline AC-13 & PCNA-like & Pleomórfico (tipo PCNA) \\
\hline AC-14 & CENP-F-like & Pleomórfico (tipo CENP-F) \\
\hline AC-15 & Cytoplasmic fibrillar linear & Citoplasmático filamentoso linear \\
\hline AC-16 & Cytoplasmic fibrillar filamentous & Citoplasmático filamentoso fibrilar \\
\hline AC-17 & Cytoplasmic fibrillar segmental & Citoplasmático filamentoso segmentar \\
\hline AC-18 & Cytoplasmic discrete dots/GW body-like & Citoplasmático granular (grânulos isolados) \\
\hline AC-19 & Cytoplasmic dense fine speckled & Citoplasmático granular fino denso \\
\hline AC-20 & Cytoplasmic fine speckled & Citoplasmático granular fino \\
\hline AC-21 & Cytoplasmic reticular/AMA & Citoplasmático reticular (tipo mitocondrial) \\
\hline AC-22 & Polar/Golgi-like & Citoplasmático polar (tipo Golgi) \\
\hline AC-23 & Rods and rings & Citoplasmático anéis e bastonetes \\
\hline AC-24 & Centrosome & Centrossoma \\
\hline AC-25 & Spindle fibers & Fuso mitótico \\
\hline AC-26 & NuMA-like & Fuso mitótico (NuMA-1) \\
\hline AC-27 & Intercellular bridge & Ponte intercelular \\
\hline AC-28 & Mitotic chromosomal coat & Envelope cromossómico \\
\hline AC-29 & - & Nuclear granular (tipo topoisomerase I/ ScL-70) \\
\hline
\end{tabular}

Um acordo mais abrangente e consensual para todas as terminologias significa uma melhoria substancial na forma como os laboratórios contribuem para o processo de diagnóstico, bem como na descrição inequívoca dos resultados.

\section{CONCLUSÃO}

Este trabalho demonstra o potencial positivo da colaboração entre laboratórios para gerar consensos que contribuem para a melhoria do acompanhamento dos doentes. O uso e a aceitação dos padrões do ICAP em Portugal só serão possíveis se a tradução para o português for aceite por um grande número de laboratórios e se existir o envolvimento alargado dos médicos, que são os principais utilizadores dos resultados laboratoriais. Deverá existir, como próximo passo, um plano de disseminação e discussão da informação agora publicada.

\section{PROTEÇÃO DE PESSOAS E ANIMAIS}

Os autores declaram que os procedimentos seguidos estavam de acordo com os regulamentos estabelecidos pelos responsáveis da Comissão de Investigação Clínica e Ética e de acordo com a Declaração de Helsínquia da Associação Médica Mundial atualizada em 2013.

\section{CONFIDENCIALIDADE DOS DADOS}

Os autores declaram ter seguido os protocolos do seu centro de trabalho acerca da publicação de dados.

\section{CONFLITOS DE INTERESSE}

Os autores declaram não ter conflitos de interesse relacionados com o presente trabalho.

\section{FONTES DE FINANCIAMENTO}

Este projeto não recebeu qualquer apoio financeiro. 


\section{REFERÊNCIAS}

1. Solomon D, Kavanaugh A, Schur P, and the American College of Rheumatology and Ad Hoc Committee on Immunologic Testing Guidelines. Evidence-based guidelines for the use of immunologic tests: Antinuclear antibody testing. Arthritis Rheum. 2002;47:434-44.

2. Agmon-Levin N, Damoiseaux J, Kallenberg C, Sack U, Witte T, Herold $\mathrm{M}$, et al. International recommendations for the assessment of autoantibodies to cellular antigens referred to as anti-nuclear antibodies. Ann Rheum Dis. 2014;73:17-23.

3. Damoiseaux J, Andrade L, Carballo O, Conrad K, Francescantonio P, Fritzler M, et al. Clinical relevance of HEp-2 indirect immunofluorescent patterns: the International Consensus on ANA patterns (ICAP) perspective. Ann of the Rheum Dis. 2019;78:879-89.

4. Wiik AS. Guidelines for antinuclear antibody testing. EJIFCC. 2006;17:134-40.

5. Chan E, Damoiseaux J, Carballo O, Conrad K, de Melo Cruvinel W, Francescantonio P, et al. Report of the First International Consensus on Standardized Nomenclature of Antinuclear Antibody HEp-2 Cell Patterns 2014-2015. Front Immunol. 2015;6:412.

6. Damoiseaux J, Mühlen C, Garcia-De La Torre I, Carballo O, Cruvinel
W, Francescantonio $P$, et al. International consensus on ANA patterns (ICAP): the bumpy road towards a consensus on reporting ANA results. Auto Immun Highlights. 2016;7:1-8.

7. Van Blerk M, Van Campenhout C, Bossuyt X, Duchateau J, Humbel R, Servais $G$, et al. Current practices in antinuclear antibody testing: results from the Belgian External Quality Assessment Scheme. Clin Chem Lab Med. 2009;47:1-8.

8. Damoiseaux J. The perspective on standardisation and harmonisation: the viewpoint of the EASI president. Auto Immun Highlights. 2020;1-7.

9. Dellavance A, Junior A, Cintra A, Ximenes A, Nuccitelli B, Muhlen von C, et al. The first Brazilian Consensus for Standardization of ANA in HEp-2 Cells. J Bras Patol Med Lab. 2001;38:207-16.

10. Dellavance A, Júnior A, Cintra A, Ximenes A, Nuccitelli B, Taliberti B, et al. II Consenso Brasileiro de Fator Antinuclear em Células HEp2: definitions for standardization of autoantibody testing against the nucleus (ANA HEp-2), nucleolus, cytoplasm and mitotic apparatus, as well as its clinical associations. Rev Bras Reumatol. 2003;43:129-40.

11. Meroni P, Schur P. ANA screening: an old test with new recommendations. Ann Rheum Dis. 2010;69:1420-2. 